\title{
Espondilodiscite como Manifestação Clínica de Endocardite Infecciosa
}

\author{
Daniela Calderaro, Tatiana F.G.Galvão, Renato Scotti Bagnatori, Bruno Caramelli
}

São Paulo, SP

\begin{abstract}
Homem de 68 anos, previamente hígido, foi admitido em enfermaria ortopédica devido a dor lombar de forte intensidade, incapacitante para deambulação, iniciada há 2 semanas, sem história de trauma. Concomitantemente, apresentava febre e calafrios. Ao exame físico, apresentava-se em regular estado geral, sem alterações neurológicas, com propedêutica de insuficiências aórtica e mitral, sem sinais de insuficiência cardíaca e com dor à palpação de apófise espinhosa da $12^{a}$ vértebra torácica. Exames laboratoriais revelaram leucocitose com desvio à esquerda (leucócitos $=20.500$; 26 bastonetes/ 65 segmentados), e intensa atividade inflamatória, com velocidade de hemossedimentação de $78 \mathrm{~mm}$ (normal: 10-15mm) e 97,2 mcg/ml de proteína C-reativa (normal: $<5 \mathrm{mcg} / \mathrm{ml}$ ). Identificado em todos os 3 pares de hemocultura Streptococcus constellatus. Ao eletrocardiograma, apenas discretas alterações da repolarização. A suspeita clínica de espondilodiscite foi confirmada por típica imagem na ressonância nuclear magnética (figs. 1 e 2), sem sinais de instabilidade da coluna. Investigação complementada com ecocardiograma que corroborou a propedêutica cardiológica, evideciando insuficiência aórtica importante e insuficiência mitral moderada, com vegetações pequenas e pedunculadas em ambas as valvas. Preenchidos assim critérios maiores de Duke ${ }^{1}$, microbiológico e ecocardiográfico, para endocardite infecciosa. Iniciada vancomicina com rápida melhora da dor lombar e da curva febril. Após um mês o paciente desenvolveu franca insuficiência cardíaca, apesar do uso de vasodilatadores, e recidiva da febre. Repetido o ecodopplercardiograma, que mostrou piora da insuficiência mitral, quantificada como importante, além das mesmas alterações detectadas no exame prévio. Foi indicado tratamento cirúrgico das valvas aórtica e mitral, com substituição de ambas por próteses biológicas. Havia vegetações em
\end{abstract}

Instituto do Coração do Hospital das Clínicas - FMUSP

Correspondência: Daniela Calderaro - INCOR - Av. Dr Eneas C Aguiar, 44 Cep 05403-000 - São Paulo, SP - E-mail: daniela.calderaro@incor.usp.br Recebido para publicação em 19/11/02

Aceito em 31/3/03

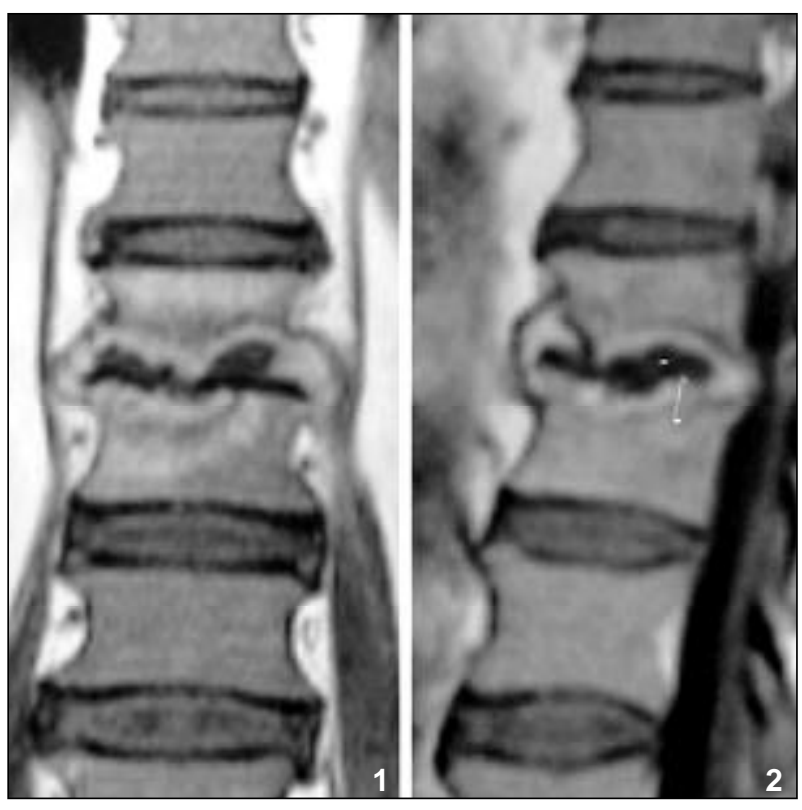

Fig. 1 e 2 - Imagens adquiridas em T-1 por ressonância nuclear magnética em planos frontal (figura 1) e sagital (figura 2) após contraste com gadolíneo. Observado hiposinal em disco vertebral entre T12 - L1 e áreas osteolíticas nos corpos vertebrais adjacentes com realce heterogêneo.

ambas as valvas, além de perfurações circulares em folhetos coronariano esquerdo e não coronariano da valva aórtica. Não havia extensão paravalvar da endocardite e as culturas (sangue e valvas) resultaram negativas. O paciente teve excelente recuperação e completou 8 semanas de antibioticoterapia (nos casos de endocardite infecciosa associada a espondilodiscite, a terapêutica antibiótica deve ser mais prolongada, durando no mínimo 6 semanas e até mesmo 3 meses $^{2}$ ).

A endocardite infecciosa continua a ser uma doença de elevada morbi-mortalidade a despeito dos grandes avanços diagnósticos e terapêuticos, com estimativas recentes de 12 a $15 \%$ de mortalidade na fase intra-hospitalar ${ }^{3}$. Entre os fatores prognósticos, ressaltam-se os eventos embólicos e precocidades diagnóstica e terapêutica. Embora não haja o conceito formal da pesquisa sistemática da associação 
entre espondilodiscite e endocardite, há relatos de incidência de 10 a $15 \%$ de espondilodiscite em pacientes com endocardite, principalmente quando se trata de etiologia estreptococcica ${ }^{2,4}$.Nesses casos, a exemplo do que observamos, o sintoma ortopédico pode ser o predominante.

Acreditamos que esta comorbidade deva ser sempre considerada e que pacientes com espondilodiscite que apre- sentem sopro à ausculta cardíaca, ou fatores de risco para endocardite, devam ser submetidos precocemente a ecocardiograma e hemoculturas. Por outro lado, nos casos de pacientes em tratamento de endocardite infecciosa que apresentem dor lombar ou dorsal, ou ainda nos casos de pesquisa de focos infecciosos metastáticos, deve-se fazer avaliação da coluna vertebral.

\section{Referências}

1. Durack DT, Lukes AS, Bright DK. New criteria for diagnosis of infective endocarditis: utilization of specific echocardiographic findings. Duke Endocarditis Service. Am J Med 1994; 96:200-9.

2. Le Moal G, Roblot F, Paccalin M, et al. Clinical and laboratory characteristics of infective endocarditis when associated with spondilodyscitis. Eur J Clin Microbiol Infect Dis 2002; 21: 671-5.
3. Mauri L, de Lemos JA, O'Gara PT. Infective endocarditis. Curr Probl Cardiol $2001 ; 26: 560-604$

4. Morelli S, Carmenini E, Caporossi AP, Aguglia G, Bernardo ML, Gurgo AM Spondylodiscitis and infective endocarditis: case studies and review of the literature. Spine 2001; 26: 499-500. 